\title{
Detection of peripheral ventilation inhomogeneity in smokers
}

\author{
DJ COTTON MD FRCPC, JT MINK BSc, BL GRAHAM PhD \\ Respiratory Division, Department of Medicine, Royal University Hospital, \\ University of Saskatchewan, Saskatoon, Saskatchewan
}

DJ CotTon, JT Mink, BL Graham. Detection of peripheral ventilation inhomogeneity in smokers. Can Respir J 1997;4(1):27-33.

BACKGROUND: In smokers, 'small airways' narrowing alters the conventional, vital capacity single breath washout (SBWVC). Although, in some studies, the test predicts smokers at risk of developing chronic airflow limitation, its wide variability partly explains its poor positive predictive value. An alternative explanation for the test's poor predictive value is that it may not accurately reflect small airway narrowing in the lung periphery.

OBJECTIVE: To determine whether smoke-induced increases in ventilation inhomogeneity differ between SBWvC manoeuvres, which augment topographical (apexto-base) ventilation inhomogeneity, and submaximal manoeuvres (SBWSM), which enhance peripheral ventilation inhomogeneity.

STUDY GROUP AND DESIGN: Cross-sectional study of 21 current smokers and 21 nonsmokers with similar age and forced expiratory volumes in $1 \mathrm{~s}\left(\mathrm{FEV}_{1}\right)$.

METHODS: Smokers and nonsmokers performed SBW with either slow vital capacity inhalation and exhalation of test gas without breath holding $\left(\mathrm{SBW}_{\mathrm{VC}}\right)$; or slow inhalation of test gas from functional residual capacity to one-half inspiratory capacity and, after $0 \mathrm{~s}$ or $10 \mathrm{~s}$ of breath holding, slow exhalation to residual volume (SBW SM). For all SBW the normalized phase III helium slope $\left(S_{n}\right)$, closing capacity (CC) as a percentage of total lung capacity (TLC) and mixing efficiency $\left(\mathrm{E}_{\mathrm{mix}}\right)$ were measured.

RESULTS: For SBWVC, smoking had no effect on $\mathrm{S}_{\mathrm{n}}$ or $\mathrm{E}_{\text {mix. }}$. However, CC/TLC was increased in smokers $(\mathrm{P}<0.05)$, but did not correlate with pack years or age. For SBW SM, smoking had no effect on $\mathrm{E}_{\operatorname{mix}}$ or CC/TLC, but resulted in a steeper $S_{n}(P<0.05)$, which decreased more with breath holding $(\mathrm{P}<0.01)$ and correlated with pack years $(\mathrm{P}<0.05)$ at $0 \mathrm{~s}$ but not $10 \mathrm{~s}$ of breath holding.

CONCLUSIONS: In smokers with normal $\mathrm{FEV}_{1}, \mathrm{SBW}_{\mathrm{SM}}$ manoeuvres reveal increases in breath hold time-dependent ventilation inhomogeneity in the lung periphery, not detected by conventional SBWVC.

Key Words: Lung function, Mixing efficiency, Phase III slope, Single breath washout, Small airways, Smoking

\section{Détection de l'inhomogénéité de la ventilation périphérique chez des fumeurs}

HISTORIQUE : Chez les fumeurs, l'obstruction des «petites voies aériennes » modifie le test conventionnel de rinçage de l'azote en respiration unique basé sur la capacité vitale (SBWVC). Bien que dans certaines études, ce test prédise quels sont les fumeurs susceptibles de développer une obstruction chronique du débit aérien, l'étendue de sa variabilité explique en partie la médiocrité de sa valeur prédictive positive. Une autre explication pour la médiocrité de la valeur prédictive de ce test pourrait provenir du fait qu'il ne reflète pas exactement l'obstruction des petites voies aériennes périphériques.

OBJECTIF : Déterminer si les augmentations de l'inhomogénéité de la ventilation induite par la fumée varient entre les épreuves de SBWvC, qui augmentent l'inhomogénéité de la ventilation topographique (de l'apex aux bases), et les épreuves sous-maximales (SBWSM), qui accroissent l'inhomogénéité de la ventilation périphérique.

GROUPE D'ÉTUDE ET MODÈLE : Étude transversale de 21 fumeurs courants et de 21 non fumeurs, d'âge similaire et avec des volumes expiratoires maximums/seconde (VEMS) semblables.

MÉTHODES : Des fumeurs et des non fumeurs ont été soumis au test de rinçage de l'azote en respiration unique, soit en inhalant lentement jusqu'à la capacité vitale et en expirant le gaz test d'un

Correspondence and reprints: Dr DJ Cotton, Respiratory Division, Department of Medicine, Royal University Hospital, Room 537, Ellis Hall, Saskatoon, Saskatchewan S7N OW8. Telephone 306-966-7947, fax 306-966-8021 
seul coup $\left(\mathrm{SBW}_{\mathrm{VC}}\right)$; ou en inhalant lentement le gaz test à partir de la capacité résiduelle fonctionnelle jusqu'à la première moitié de la capacité inspiratoire, et après $0 \mathrm{~s}$ ou $10 \mathrm{~s}$ en apnée, en expirant lentement jusqu'au volume résiduel $\left(\mathrm{SBW}_{\mathrm{SM}}\right)$. Pour tous les tests de rinçage de l'azote en respiration unique, on a mesuré la pente de la phase III de l'hélium normalisée $\left(S_{n}\right)$, la capacité de fermeture $(\mathrm{CC})$ en pourcentage de la capacité pulmonaire totale (TLC) et l'efficacité du mélange ( $\left.\mathrm{E}_{\mathrm{mix}}\right)$.

RÉSULTATS : Pour les SBWVC, fumer n'avait aucun effet sur $\mathrm{S}_{\mathrm{n}}$ ou sur $\mathrm{E}_{\mathrm{mix}}$. Cependant, le rapport CC/TLC augmentait chez les fumeurs $(\mathrm{P}<0,05)$, mais n'avait pas de corrélation avec le nombre de paquets/année et l'âge. Pour les SBW $\mathrm{SM}$, fumer n'avait aucun effet sur $E_{\text {mix }}$ ou sur CC/TLC, mais résultait en une $S_{n}$ plus abrupte $(\mathrm{P}<0,05)$, qui diminuait plus en apnée $(\mathrm{P}<0,01)$ et corrélait avec le nombre de paquets/année $(\mathrm{P}<0,05)$ à $0 \mathrm{~s}$ mais pas à $10 \mathrm{~s}$ en apnée. CONCLUSIONS : Chez les fumeurs dont le VEMS est normal, les épreuves de SBW $W_{S M}$ révèlent des augmentations de l'inhomogénéité de la ventilation dans les voies aériennes périphériques dépendante du temps d'apnée et qui n'est pas décelée par le test conventionnel de SBWvC.
$\mathrm{T}$ he earliest pathological lesions in the lungs of young, relatively asymptomatic smokers dying accidentally are respiratory bronchiolitis (1). Although small airways contribute little to the overall resistance to airflow in normal subjects, bronchiolar resistance also increases in the lung periphery of patients who develop smoke-induced chronic airflow limitation (CAL) (2) as a result of bronchiolar inflammation and fibrosis (3). Initial structure-function correlates in smokers with normal forced expired flow rates suggested that conventional vital capacity single breath washout (SBWVC) manoeuvres might be able to detect small airway narrowing (3). Cross-sectional studies using SBWvC revealed that approximately $50 \%$ of smokers had an abnormal phase III slope (4). Subsequent prospective studies in smokers demonstrated a correlation between an abnormal initial phase III slope (5) and closing volume (CV) (6) and a more rapid decline in forced expiratory volume in $1 \mathrm{~s}\left(\mathrm{FEV}_{1}\right)$, but other studies did not $(7,8)$.

The most often cited reason for the poor correlation of SBWVC with those who subsequently experience rapid declines in $\mathrm{FEV}_{1}(9)$ is the complexity and poor reproducibility of the test (10). However, other factors may be important, including standardizing previous volume history (11), inspired volume $\left(\mathrm{V}_{\mathrm{insp}}\right)$, flow rate and breath hold time $\left(\mathrm{t}_{\mathrm{BH}}\right)$ (12). Alternatively, the failure of more recent studies to significantly relate inflammation in the membranous bronchioles and macroscopic emphysema, measured pathologically, with reductions in $\mathrm{FEV}_{1}$ in smokers raises questions about the usefulness of currently used measurements of emphysema scores and inflammatory bronchiolitis in the development of disabling CAL $(13,14)$.

Recent analyses of gas mixing in the lung $(15,16)$ suggest that ventilation inhomogeneity in the lung periphery increases with decreasing $\mathrm{V}_{\text {insp }}$ and becomes more dependent on tBH (17). We hypothesized that the early effects of smoking on the distribution of ventilation in the lung periphery might be more readily detected using submaximal single breath manoeuvres (SBWSM), initiated from functional residual capacity (FRC). We describe refinements of the SBW manoeuvre using submaximal manoeuvres and a comparison of this test with SBWVC in two groups of subjects: smokers with normal lung function; and a comparable group of healthy nonsmokers. For each single breath manoeuvre we measured the normalized phase III slope for helium $\left(S_{n}\right)$, the mixing efficiency $\left(E_{m i x}\right)$ and the closing capacity (CC).

\section{PATIENTS AND METHODS}

Study group: Twenty-one smokers and 21 nonsmokers, recruited from the community and from hospital personnel, were screened using a respiratory questionnaire and met the following criteria: no current history of a cold in the past two weeks and no use of respiratory medications; and no doctordiagnosed history of chronic bronchitis, asthma, emphysema, hypertension or heart disease. Both smokers and nonsmokers also performed spirometric tests using standard techniques before the study. For both groups, inclusion criteria were that forced vital capacity (FVC), FEV 1 and maximal midexpiratory flow rates $\left(\mathrm{FEF}_{25-75}\right)$ were within the $95 \%$ confidence limits of normal using previously reported regressions (18). Smokers had a current cigarette consumption of at least 10 cigarettes per day and a cumulative exposure of at least four pack years. Nonsmokers had no current exposure and had smoked fewer than 100 cigarettes in their lifetime.

Apparatus and equipment: The apparatus has been previously described in detail $(19,20)$. Subjects breathed through a low dead space two-way valve. Test gas consisted of $10 \%$ helium, $0.3 \%$ carbon monoxide (not used in the present analysis) in $21 \%$ oxygen, and balance nitrogen. Flow and volume were measured using a pneumotachograph (Fleisch No 3, A Fleisch, Switzerland) mounted, with linearizing tubes, in the wall of a bag-in-box system. Helium concentration was measured continuously throughout the manoeuvres by a mass spectrometer (MGA 1100, Perkin Elmer, California). The capillary line was mounted within the body of the Rudolph valve. Throughout each SBW, including two to three preceding tidal breaths and a standardized deep breath, flow, volume and helium signals were stored digitally $(50 \mathrm{~Hz})$ for later computer analysis.

Protocol: Subjects were studied in the seated position at rest with a nose clip in place. In the two to three breaths before the commencement of testing, helium concentration was monitored, and testing did not continue if significant background helium concentration was detected from the previous SBW (20). To standardize for the relationship of the testing interval to any previous deep breaths or sighs, as well as for fluctuations in resting lung volume (FRC) and for the exhaled flow rate immediately before testing, all manoeuvres were preceded by a standardized deep breath of room air. This consisted of slow $(0.5 \mathrm{~L} / \mathrm{s})$ inhalation from FRC to total lung capacity (TLC) and, after $5 \mathrm{~s}$ of breath holding, slow $(0.5 \mathrm{~L} / \mathrm{s})$ exhalation to the prescribed initial lung volume (either FRC or residual volume $[\mathrm{RV}])(19,20)$. From previous measure- 
ments of inspiratory capacity (IC) and vital capacity, an individualized volume versus time 'template' of the prescribed SBW was tailored for each subject and displayed on a monitor (20). The volume-time template included the preceding deep breath and the prescribed manoeuvre, with all flows set at $0.5 \mathrm{~L} / \mathrm{s}$. The subject's instantaneous signal of volume versus time for the manoeuvre in progress was superimposed on the template at the onset of the deep breath. The subject was asked to perform the test by superimposing the actual volume versus time tracing on the template. Success in initiating the submaximal manoeuvres consistently at FRC depended on coaching subjects to reach TLC during the deep breath, repositioning the subject's signal to align visually with the template at this juncture and displaying the subject's IC in the template during the expiratory phase of the deep breath. The biofeedback of the single breath manoeuvre ensured that the SBW could be performed within narrow tolerances for flow, volume and $t_{\mathrm{BH}}$, even in untrained subjects (21). As part of a larger study to examine both ventilation inhomogeneity and changes in the three-equation diffusing capacity (22) the following manoeuvres were performed: first, SBWVC, which were conventional single breath manoeuvres consisting of slow inhalation of test gas from RV to TLC without breath holding, and slow exhalation to RV; and second, SBWSM, which were submaximal manoeuvres consisting of slow inhalation of test gas from FRC to one-half IC, and after $0 \mathrm{~s}$ or $10 \mathrm{~s}$ of breath holding, slow exhalation to RV. Analysis: For each SBW the $\mathrm{V}_{\text {insp }}$ and expired volume $\left(\mathrm{V}_{\text {exp }}\right)$, inspiratory and expiratory times ( $\mathrm{t}_{\text {insp }}$ and $\left.\mathrm{t}_{\mathrm{exp}}\right)$ and tBH $_{\mathrm{BH}}$ were measured. RV was calculated by measuring the mass of helium inhaled and the mass of helium exhaled to determine the mass of helium remaining in the lung, as previously described (20). It was assumed that the mean helium concentration in the lung at RV was equal to the measured helium concentration at end-expiration. For each breath the $\mathrm{S}_{\mathrm{n}}(\Delta \mathrm{He} / \mathrm{L})$ between $33 \%$ and $67 \%$ of the exhaled volume was measured by linear regression analysis, and that the calculation did not infringe on the onset of $\mathrm{CV}$ was visually confirmed. $\mathrm{S}_{\mathrm{n}}$ was calculated by dividing $\Delta \mathrm{He} / \mathrm{L}$ by the measured ideal, mean end-inspired alveolar helium concentration ([He]A PRED), predicted for the case of homogeneous gas mixing in a lung with a known dead space and a single alveolar space, as previously described (20,23). Emix was calculated by dividing [He]A PRED by the measured mean helium concentration in all the exhaled gas after dead space washout (20). For each breath dead space was measured by the methods of both Fowler $\left(V_{d}\right)(24)$ and Bohr $\left(V_{d}\right.$ Bohr). CV was also calculated using a previously described computer algorithm (19). CC was (CV + RV) and was normalized by dividing by TLC.

Statistics: Group mean data for smokers and nonsmokers were compared using unpaired Student's $t$ tests. Differences due to the SBW manoeuvre and to $t_{B H}$ for $S_{B W}$ were assessed using paired Student's $t$ tests in both smokers and nonsmokers. Correlations were determined by linear regression analysis. In this study the potential exists for type II errors since the study groups were small and the power of the
TABLE 1

Conventional single breath washouts

\begin{tabular}{lcc}
\hline Variables & Smokers & Nonsmokers \\
\hline$V_{\text {insp }}(\mathrm{L})$ & $4.35 \pm 1.17$ & $4.45 \pm 0.93$ \\
$\mathrm{~V}_{\exp }(\mathrm{L})$ & $4.34 \pm 1.09$ & $4.46 \pm 0.92$ \\
$\mathrm{~V}_{\max }(\mathrm{L})$ & $6.18 \pm 1.57$ & $6.13 \pm 1.24$ \\
$\mathrm{RV}(\mathrm{L})$ & $1.84 \pm 0.57$ & $1.67 \pm 0.42$ \\
$\mathrm{~V}_{\mathrm{d}}(\mathrm{L})$ & $0.22 \pm 0.08$ & $0.22 \pm 0.07$ \\
$\mathrm{~V}_{\mathrm{d} \text { Bohr }}(\mathrm{L})$ & $0.72 \pm 34$ & $0.67 \pm 0.38$ \\
$t_{\text {insp }}(\mathrm{s})$ & $6.7 \pm 2.0$ & $7.1 \pm 1.7$ \\
$t_{\exp }(\mathrm{s})$ & $9.4 \pm 2.1$ & $9.3 \pm 1.8$ \\
$t_{B H}(\mathrm{~s})$ & $1.3 \pm 0.5$ & $1.4 \pm 0.5$ \\
$\mathrm{E}_{\operatorname{mix}}(\%)$ & $96.0 \pm 1.6$ & $96.8 \pm 1.3$ \\
$\mathrm{~S}_{n}\left(\mathrm{~mL}^{-1}\right)$ & $-16 \pm 8$ & $-14 \pm 8$ \\
$\mathrm{CC} / \mathrm{TLC}(\%)$ & $42.4 \pm 4.4$ & $37.8 \pm 5.6^{*}$ \\
\hline
\end{tabular}

*Significant difference between smokers and nonsmokers $(P<0.001)$. Variables are mean $\pm 1 S D$ for conventional slow vital capacity manoeuvres without breath holding $\left(S B W_{V C}\right)$. CC Closing capacity, normalized by dividing by total lung capacity (TLC) (CC/TLC); Emix Mixing efficiency; $R V$ Residual volume; $S_{n}$ Normalized phase III slope for helium; $t_{B H}$ Breath hold time; $t_{\exp }$ Expiratory time; $t_{\text {insp }}$ Inspiratory time; $V_{d}$ Fowler dead space; $V_{d}$ Bohr Bohr dead space; $V_{\text {exp }}$ Expired volume; $V_{\text {insp }}$ Inspired volume; $V_{\max }$ Maximum volume, or TLC for these manoeuvres

statistical approach is potentially weak. This needs to be considered when interpreting the apparent lack of statistical associations among variables, particularly when the $\mathrm{P}$ value approaches significance $(\mathrm{P}<0.05)$.

\section{RESULTS}

The smoking and nonsmoking groups were similar in terms of sex distribution (smokers, 12 women and nine men; nonsmokers, 10 women and 11 men), age (smokers, 39 \pm 8 years; nonsmokers, $38 \pm 7$ years, mean \pm 1 SD) and height (smokers, $172 \pm 10 \mathrm{~cm}$; nonsmokers, $174 \pm 10 \mathrm{~cm}$ ). There were no significant differences in FVC (smokers, $105 \pm 10 \%$ predicted; nonsmokers, $101 \pm 8 \%$ predicted) or $\mathrm{FEV}_{1}$ (smokers, $100 \pm 9 \%$ predicted; nonsmokers, $102 \pm 8 \%$ predicted). The $\mathrm{FEF}_{25-75}$ was smaller $(\mathrm{P}<0.05)$ in smokers $(90 \pm 24 \%$ predicted) than in nonsmokers (106 $\pm 21 \%$ predicted). The smokers had a mean of $21 \pm 12$ pack years of cigarette exposure (range four to 55 pack years). Six of the smokers, but none of the nonsmokers, had symptoms of chronic bronchitis by questionnaire. Nine smokers were short of breath when hurrying on the level or walking up a slight hill, compared with none of the nonsmokers.

For SBWVC (Table 1) there were no differences between smokers and nonsmokers in $\mathrm{V}_{\text {insp }}$ or $\mathrm{V}_{\text {exp }}$ or times, in maximal volume $\left(\mathrm{V}_{\max }\right), \mathrm{RV}, \mathrm{V}_{\mathrm{d}}$ or $\mathrm{V}_{\mathrm{d}}$ Bohr. There were also no differences between smokers and nonsmokers in $\mathrm{E}_{\mathrm{mix}}$ or $\mathrm{S}_{\mathrm{n}}$, but $\mathrm{CC} / \mathrm{TLC}$, although greater in smokers $(\mathrm{P}<0.01)$, did not correlate with pack years. CC/TLC correlated significantly with age in nonsmokers $\left(\mathrm{r}^{2}=0.37, \mathrm{P}<0.01\right)$, but not in smokers, primarily because CC/TLC was higher in the younger smokers (Figure 1).

For SBWSM (Table 2) there were no differences between smokers and nonsmokers in $\mathrm{V}_{\text {insp }}, \mathrm{V}_{\text {exp }}, \mathrm{V}_{\max }, \mathrm{RV}, \mathrm{V}_{\mathrm{d}}, \mathrm{V}_{\mathrm{d}}$ Bohr, tinsp, texp, tBH, Emix or CC/TLC at either tBH. However, 


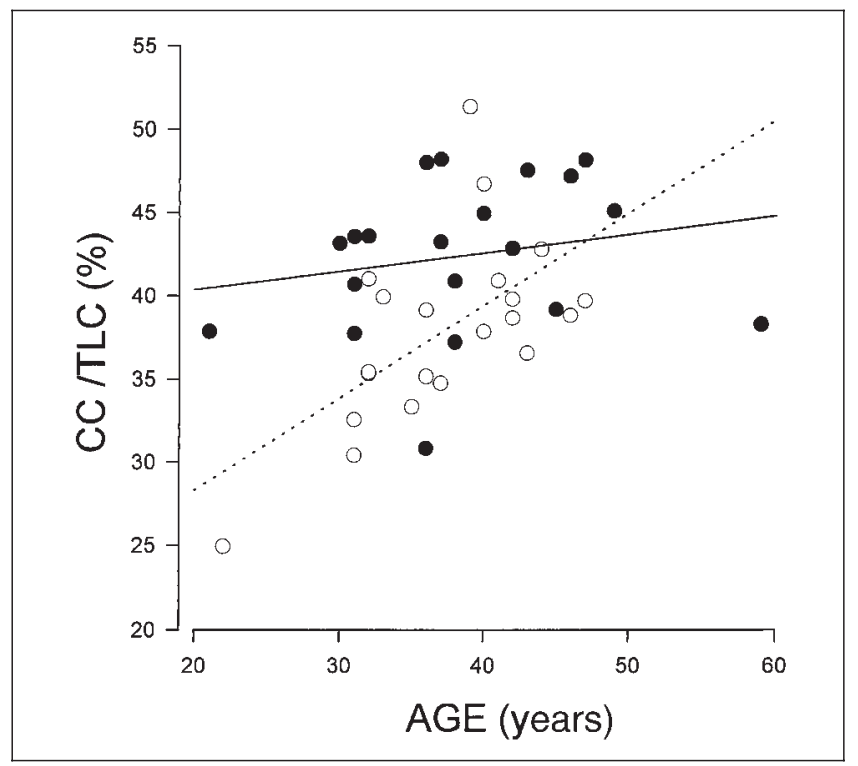

Figure 1) Closing capacity (CC)/total lung capacity (TLC) in smokers $(\bullet$, solid linear regression line) and nonsmokers $(\bigcirc$, dashed linear regression line) as a function of age (in years) for vital capacity single breath washout $\left(S B W_{\mathrm{VC}}\right)$. There was a significant correlation in nonsmokers $\left(r^{2}=0.37, P<0.01\right)$, but not in smokers. Similar correlations in nonsmokers, but not smokers, were found for submaximal $S W B\left(S B W_{\mathrm{SM}}\right)$ at both breath hold times $(P<0.01)$

TABLE 2

Submaximal single breath washouts

\begin{tabular}{|c|c|c|c|c|}
\hline \multirow[b]{2}{*}{ Variables } & \multicolumn{2}{|c|}{$0 \mathrm{~s}$ breath holding } & \multicolumn{2}{|c|}{$10 \mathrm{~s}$ breath holding } \\
\hline & Smokers & Nonsmokers & Smokers & Nonsmokers \\
\hline$V_{\text {insp }}(\mathrm{L})$ & $1.5 \pm 0.4$ & $1.6 \pm 0.3$ & $1.6 \pm 0.4$ & $1.7 \pm 0.3$ \\
\hline$V_{\exp }(\mathrm{L})$ & $3.0 \pm 1.0$ & $3.0 \pm 0.7$ & $3.0 \pm 1.0$ & $2.9 \pm 0.8$ \\
\hline $\mathrm{V}_{\max }(\mathrm{L})$ & $4.92 \pm 1.4$ & $4.74 \pm 1.07$ & $4.99 \pm 1.39$ & $4.79 \pm 1.12$ \\
\hline $\mathrm{RV}(\mathrm{L})$ & $1.91 \pm 0.49$ & $1.75 \pm 0.44$ & $2.01 \pm 0.52$ & $1.84 \pm 0.43$ \\
\hline $\mathrm{V}_{\mathrm{d}}(\mathrm{L})$ & $0.15 \pm 0.06$ & $0.16 \pm 0.04$ & $0.10 \pm 0.06^{\dagger}$ & $0.10 \pm 0.03^{\dagger}$ \\
\hline $\mathrm{V}_{\mathrm{d} \text { Bohr }}(\mathrm{L})$ & $0.35 \pm 0.13$ & $0.34 \pm 0.12$ & $0.23 \pm 0.12^{\dagger}$ & $0.22 \pm 0.09^{\dagger}$ \\
\hline$t_{\text {insp }}(s)$ & $2.4 \pm 0.6$ & $2.6 \pm 0.6$ & $2.7 \pm 0.8$ & $2.9 \pm 0.8$ \\
\hline$t_{\exp }(\mathrm{s})$ & $7.8 \pm 0.21$ & $7.3 \pm 1.7$ & $7.5 \pm 2.2$ & $7.5 \pm 1.6$ \\
\hline$t_{B H}(s)$ & $0.8 \pm 0.2$ & $0.8 \pm 0.2$ & $9.8 \pm 3^{\dagger}$ & $9.8 \pm 0.8^{\dagger}$ \\
\hline$E_{\text {mix }}(\%)$ & $87.9 \pm 4.1$ & $89.9 \pm 2.5$ & $91.6 \pm 3.1^{\dagger}$ & $93.1 \pm 1.7^{\dagger}$ \\
\hline $\mathrm{S}_{\mathrm{n}}\left(\mathrm{mL}^{-1}\right)$ & $-135 \pm 64$ & $-65 \pm 28^{*}$ & $-59 \pm 42^{\dagger}$ & $-28 \pm 15^{\star} \dagger$ \\
\hline CC/TLC (\%) & $40.0 \pm 7.1$ & $40.4 \pm 6.0$ & $43.9 \pm 4.9^{\dagger}$ & $41.2 \pm 5.4$ \\
\hline
\end{tabular}

Variables for submaximal single breath manoeuvres, initiated from functional residual capacity with either $0 \mathrm{~s}$ or $10 \mathrm{~s}$ of breath holding (SBW $W_{S M}$ ). *Significant differences between smokers and nonsmokers at the same breath hold time $(P<0.01)$. ${ }^{+}$Significant effects of breath holding in either smokers or nonsmokers $(P<0.01)$. CC Closing capacity, normalized by dividing by total lung capacity (TLC) (CC/TLC); $E_{\text {mix }}$ Mixing efficiency; RV Residual volume; $S_{n}$ Normalized phase III slope for helium; $t_{B H}$ Breath hold time; $t_{\text {exp }}$ Expiratory time; $t_{\text {insp }}$ Inspiratory time; $V_{d}$ Fowler dead space; $V_{d B o h r}$ Bohr dead space; $V_{\text {exp }}$ Expired volume; $V_{\text {insp }}$ Inspired volume; $V_{\max } M a x i m u m$ volume, or TLC for these manoeuvres

$\mathrm{S}_{\mathrm{n}}$ was significantly steeper at both tBHs in smokers (Table 2) and the change in $S_{n}\left(\Delta S_{n}\right)$ with t tBH was greater in smokers compared with nonsmokers. In smokers $\Delta S_{\mathrm{n}}$ was $-75 \pm 48$ $\mathrm{mL}^{-1}$, whereas in nonsmokers it was $-37 \pm 23 \mathrm{~mL}^{-1}(\mathrm{P}<0.01)$. For SBW $\mathrm{SM}_{\mathrm{M}}$ without breath holding no differences in $\mathrm{E}_{\mathrm{mix}}$,

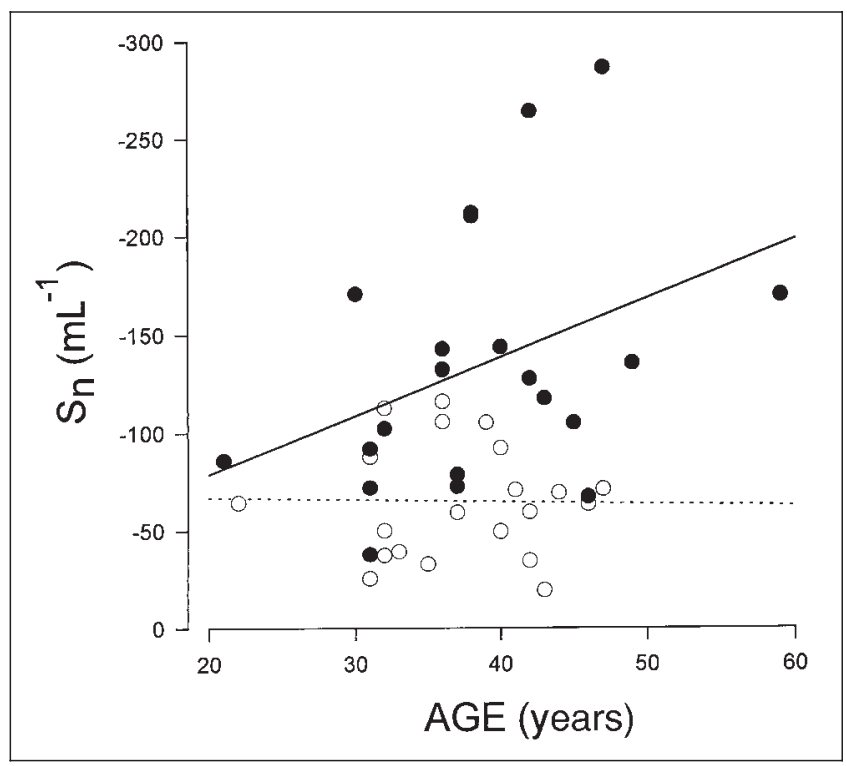

Figure 2) Normalized phase III slope $\left(S_{n}\right)$ in smokers $(\bullet$, solid linear regression line) and nonsmokers $(\mathrm{O}$, dashed linear regression line) for submaximal single breath washout without breath holding, as a function of age. The increase in $S_{n}$ with age was not significant in either group, but there was a trend in smokers $(P=0.08)$

Sn or CC/TLC were found in comparing smokers with and without chronic bronchitis or comparing smokers with and without dyspnea.

For SBWSM with $0 \mathrm{~s}$ breath holding, $\mathrm{S}_{\mathrm{n}}$ did not correlate with age in smokers $(\mathrm{P}=0.08)$ or in nonsmokers (Figure 2$)$, but correlated significantly with pack years in smokers (Figure 3). However, this correlation of $S_{n}$ with pack years was not significant at $10 \mathrm{~s}$ of breath holding. Although there was no difference between smokers and nonsmokers in $\mathrm{E}_{\operatorname{mix}}$ at either tBH, it decreased significantly with age $(\mathrm{P}<0.01)$ in both groups and at both tBHs (Figure 4). After $10 \mathrm{~s}$ of breath holding (Table 2) there were no significant effects on the lung volumes that were intentionally controlled, but $\mathrm{V}_{\mathrm{d}}, \mathrm{V}_{\mathrm{d}}$ Bohr and $S_{n}$ decreased, and $E_{\text {mix }}$ increased with breath holding in both smokers and nonsmokers $(\mathrm{P}<0.01)$. CC/TLC increased with tBH in smokers $(\mathrm{P}<0.01)$, but not in nonsmokers.

\section{DISCUSSION}

The most striking finding in this study was that $S_{n}$ was significantly steeper in smokers for SBW $\mathrm{SM}$ at both tBHS (Table 2), and correlated with pack years at $0 \mathrm{~s}$ but not $10 \mathrm{~s}$ of breath holding (Figure 3). No such differences due to smoking were evident for $\mathrm{S}_{n}$ using $\mathrm{SBW}_{\mathrm{VC}}$. This suggests

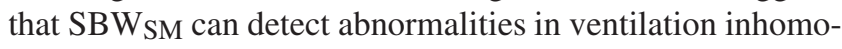
geneity in cigarette smokers, whereas previously employed SBWVC methods do not. The preferential detection of the

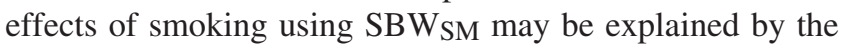
fact that several mechanisms cause heterogeneity in gas concentrations in the lung, which simultaneously influence $S_{n}$ (15). The influence of these mechanisms on $S_{n}$ is affected by lung volume, pre-inspiratory lung volume $(15,23)$ and $t_{B H}$ $(23,25,26)$. 


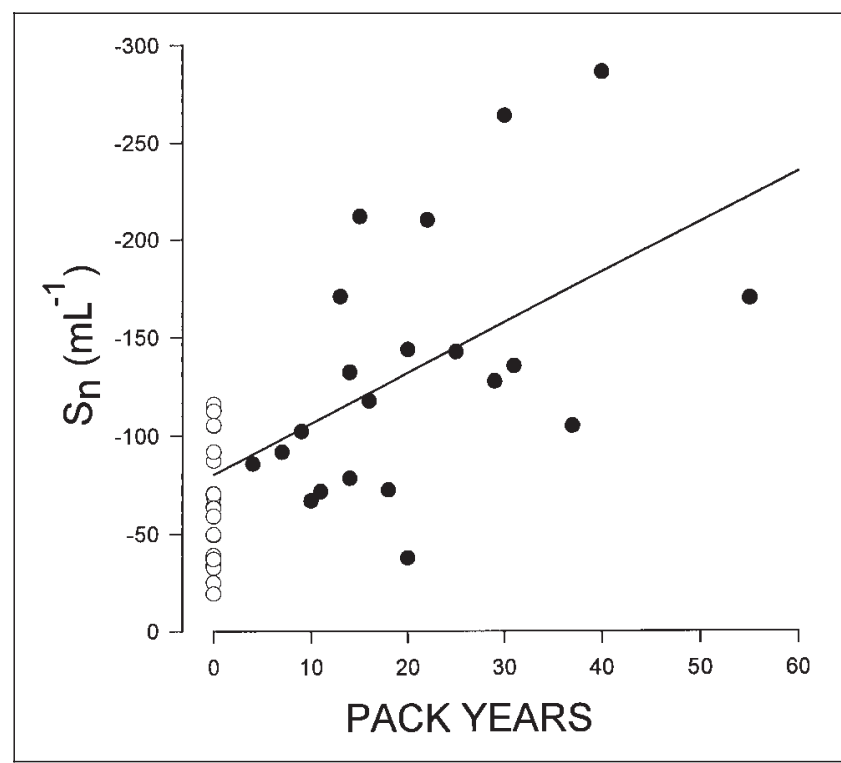

Figure 3) Normalized phase III slope $\left(S_{n}\right)$ as a function of pack years in smokers for submaximal single breath washout (SBWSM) without breath holding $\left(\bullet\right.$, solid linear regression line). $S_{n}$ for nonsmokers is also shown for comparison (O). $S_{n}$ increased significantly with pack years $\left(r^{2}=0.24, P<0.05\right)$. No such correlation existed for SBW $W_{S M}$ with 10 s of breath holding $\left(r^{2}=0.1, P>0.1\right)$

Convective-dependent inhomogeneity (inter-CDI) due to topographical (apex to base) differences in the distribution of the inspired gas contributes to $S_{n}$ and depends on concentration differences among large, anatomically remote units that possess differing specific ventilation and empty asynchronously. This type of ventilation inhomogeneity markedly decreases with increases in $V_{\text {insp }}$ when $V_{\max }$ is kept constant (23) and is quite resistant to the effects of breath holding (27). A second mechanism, similar to inter-CDI, exists on a nongravitational, intraregional basis (intra-CDI) in the lung periphery within anatomically adjacent lobes $(15,17)$. This cause of ventilation inhomogeneity decreases with breath holding as a result of gas mixing (28). Third, model analyses of gas mixing (15) indicate that a phase III slope can be generated by the interaction of diffusion and convection at branch points in the lung periphery within an asymmetric acinus (DCDI) (15). It increases with decreasing lung volume for SBW $_{\text {SM }}$ (17) and is markedly reduced by breath holding (26). Using multibreath washouts with $1 \mathrm{~L}$ tidal volumes from FRC in normal subjects, most of the phase III slope is attributed primarily to ventilation inhomogeneity in the lung periphery (29), which persists in the absence of gravity (30). In this study we assessed the relative importance of peripheral ventilation inhomogeneity in the genesis of the phase III slope by examining the effect of increasing tBH on SBWSM. The steeper $\mathrm{S}_{\mathrm{n}}$ for SBWSM in smokers at $0 \mathrm{~s}$ of breath holding and its correlation with smoking pack years as well as the greater change in $\mathrm{S}_{\mathrm{n}}$ with breath holding supports the notion that smoking alters primarily the time-dependent component of ventilation inhomogeneity, which is likely in the lung periphery (15), distal to the $3 \mathrm{~mm}$ airways (27). These tBH-

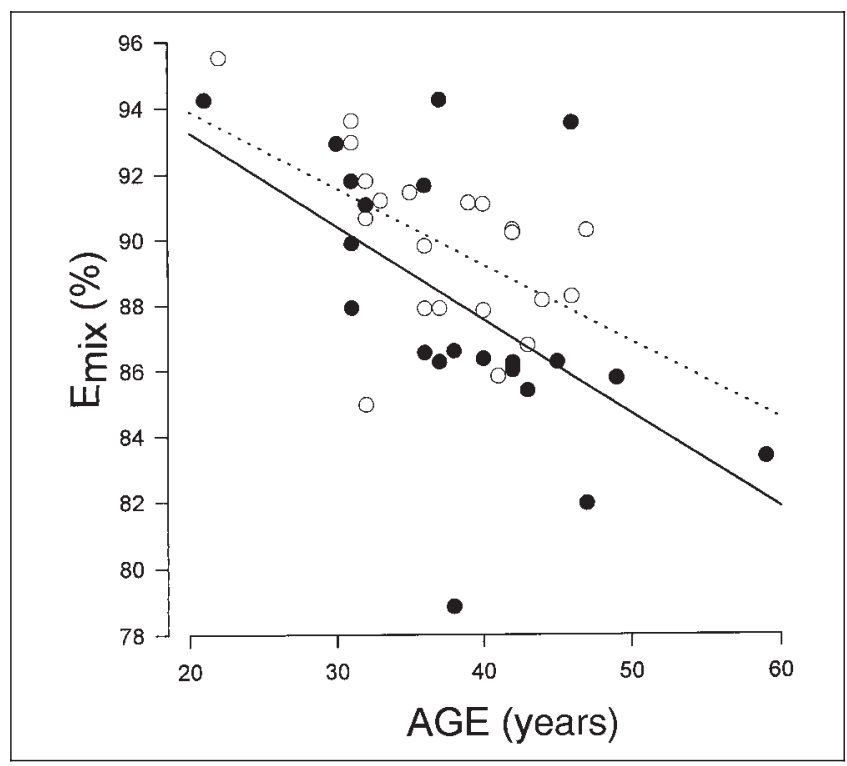

Figure 4) Mixing efficiency $\left(E_{\text {mix }}\right)$ as function of age for submaximal single breath washout without breath holding in smokers $(\bullet$, solid linear regression line) and nonsmokers $(\mathrm{O}$, dashed linear regression line). $E_{m i x}$ decreased significantly with age in both smokers $\left(r^{2}=0.38, P<0.003\right)$ and nonsmokers $\left(r^{2}=0.32, P<0.01\right)$, but there was no significant effect of smoking. Effects (not shown) were similar at $10 \mathrm{~s}$ of breath holding

dependent contributions to $S_{n}$ are likely due to DCDI as well as to intra-CDI, rather than inter-CDI $(15,23)$.

We employed a number of variations from conventional testing procedures, which were designed to reduce some of the inherent variability observed in previous measurements of ventilation inhomogeneity (4). We standardized previous volume history by preceding all manoeuvres by a standardized deep breath because intermittent deep breaths affect the subsequently measured phase III slope (19). We controlled the speed of exhalation before inhalation of test gas using a volume versus time template of the prescribed deep breath because fast versus slow exhalation to RV before performing conventional single breath manoeuvres resulted in a steeper phase III slope in smokers, but a shallower phase III slope in nonsmokers (11). We also rigidly controlled other important factors that alter ventilation distribution including the lung volume at which the SBW was initiated (FRC or RV) (31) as well as the inhaled and exhaled volumes and flows (12). Finally, we normalized the phase III slope because the slope depends on gas concentration, which, in turn, depends on specific ventilation. Dividing the phase III slope by the theoretical end-inspired alveolar helium concentration makes the measurement independent of gas concentration and hence independent of gross specific ventilation $(20,23)$.

Although we employed helium as the inert tracer gas in this study, our results are likely to be comparable with those obtained from the more traditional single breath nitrogen washout (32). Differences may exist because gases of higher molecular weight (nitrogen) would be expected to enhance the effect of smoking for SBWSM without breath holding, but lengthen the time required for gas mixing during breath 
holding and hence reduce the $\Delta \mathrm{S}_{\mathrm{n}}$ with breath holding. However, this equilibration time is relatively short for nonsmokers since $\mathrm{S}_{\mathrm{n}}$ did not fall further after about $6 \mathrm{~s}$ of breath holding in normal subjects using SBW SM manoeuvres identical to those used in this study (23). Concordance of the helium and nitrogen phase III slopes was also assessed in a group of normal subjects and patients with airway obstruction. The phase III nitrogen slope, using standard single breath nitrogen testing procedures (4), correlated strongly with $\Delta \mathrm{He} / \mathrm{L}$, measured using SBWVC manoeuvres similar to those used in this study $\left(\mathrm{r}^{2}=0.93 ; \mathrm{P}<0.001\right)(32)$.

The present results support the recent observations of Van Muylem et al (16) who examined ventilation inhomogeneity in smokers using the simultaneously measured phase III slopes for both helium and a much denser gas, sulphahexafluoride, during submaximal manoeuvres initiated at FRC, similar to those used in the present study, but with varying $\mathrm{V}_{\text {insp. They found that the change in the difference between }}$ the slopes of these two gases with lung volume was significantly greater in smokers and correlated with the degree of inflammation in the respiratory bronchioles (16). However, their smokers had more advanced smoke-induced lung involvement than the smokers in the present study.

In contrast to the significant effect of smoking on $S_{n}, E_{\text {mix }}$ was not significantly altered by smoking, but decreased significantly with age (Figure 4), as previously described (33). The explanation for the preferential effect of smoking on $\mathrm{S}_{\mathrm{n}}$, rather than $\mathrm{E}_{\text {mix }}$, may be due to the fact that the convectively determined components of $S_{n}$ are influenced by both temporal (asynchronous emptying) and spatial (unequal regional specific ventilation) determinants of ventilation inhomogeneity, whereas $\mathrm{E}_{\text {mix }}$ is affected only by changes in the spatial determinants of ventilation inhomogeneity (31). This implies that the effects of smoking on ventilation inhomogeneity may correlate more with narrowing of inflamed airways, resulting in regional alterations in flow sequencing, rather than with early emphysema, which would alter regional compliance and hence alter regional specific ventilation and decrease $\mathrm{E}_{\text {mix. }}$.

CV appears to be linked to inter-CDI mechanisms of heterogeneity in gas concentrations caused by closure of basal airways at low lung volumes (34). However, recent evidence indicates that $\mathrm{CV}$ may also be influenced by intraCDI mechanisms of ventilation inhomogeneity because CC persists in the absence of gravity (35). The fact that smoking increased CC/TLC for SBWVC but not for SBWSM manoeuvres at either $\mathrm{t}_{\mathrm{BH}}$ suggests that $\mathrm{SBW}_{\mathrm{VC}}$ manoeuvres enhance the smoke-induced increases in inter-CDI by augmenting the differences in regional gas concentration between the apex and the base of the lung (36). However, the changes in $\mathrm{CC} / \mathrm{TLC}$ for SBWVC manoeuvres did not correlate with pack years of smoking, suggesting that the effects may not relate well to cumulative exposure to cigarette smoke. For SBWVC manoeuvres we found that CC/TLC increases with age in nonsmokers, but not in smokers (Figure 1) as previously described (37). We also found a similar correlation in nonsmokers, but not in smokers, for SBW $\mathrm{SM}$ at both tBHS. Al- though age-related loss of elastic recoil could explain increased CC/TLC with age in nonsmokers (38), we paradoxically found no such relationship in smokers because CC/TLC was increased the most in younger smokers with the least exposure to cigarette smoke (Figure 1). This observation raises the possibility of a 'survivor' effect (the most affected smokers are not represented among those with the greatest number of pack years).

The results of this cross-sectional study of a relatively small group of selected smokers suggests a potential role for

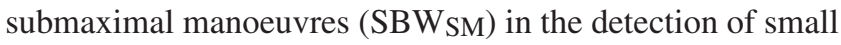
airway involvement in smokers. Although we did not assess pathological changes in the lung, the smokers in this study were similar to those studied by Niewoehner et al (1), who did find pathological changes in the small airways. Because we selected smokers with relatively little change in lung function, despite an average of 20 pack years of smoke exposure they may be even less likely than an unselected population to be at risk for progressive development of CAL. Furthermore, cross-sectional studies are influenced by uncontrolled factors that determine the initiation, cessation and continuation of the smoking habit. Finally, the size of our group is too small to address the question of whether a subpopulation (10\% to $15 \%$ ) of the smokers might be at risk of developing CAL. Nevertheless, this study does point to clear differences in ventilation inhomogeneity due to smoking that depend on physiological mechanisms that cannot be observed by analysis of conventional SBW, employed in previous studies. In this study we describe refinements of the SBW, which may provide a more specific marker of functional changes in the lung periphery, potentially allowing more precise identification of smokers at risk of subsequently developing accelerated declines in FEV 1 . The development of physiological markers of small airway narrowing may also be useful in detecting and monitoring bronchiolitis from causes other than cigarette smoking, such as that seen in patients following lung transplantation.

ACKNOWLEDGEMENTS: Supported by the Saskatchewan Lung Association, John Cameron Moorhead Foundation and the Medical Research Council of Canada.

\section{REFERENCES}

1. Niewoehner DE, Kleinerman J, Rice DB. Pathological changes in the peripheral airways of young cigarette smokers. N Engl J Med 1974;291:755-8.

2. Hogg JC, Macklem PT, Thurlbeck WM. Site and nature of airway obstruction in chronic obstructive lung disease. N Engl J Med 1968;278:1355-60.

3. Wright JL. Small airways disease: its role in chronic airflow obstruction. Semin Respir Med 1992;13:72-84.

4. Buist AS, Ross BB. Quantitative analysis of the alveolar plateau in the diagnosis of early airway obstruction. Am Rev Respir Dis 1973;108:1078-87.

5. Olofsson J, Svardsudd B, Skoogh B-E. The single breath $\mathrm{N}_{2}$-test predicts the rate of decline in FEV 1 . Eur J Respir Dis 1986;69:46-56.

6. Beaty TH, Menkes HA, Cohen BH, Newill CA. Risk factors associated with longitudinal change in pulmonary function. Am Rev Respir Dis 1984;129:660-7.

7. Marazzini L, Cavigioli G, Mastropasqua B, Pelluchi A. FEV1 decline in asymptomatic young adults: relationships with some tests of small airways function. Eur Respir J 1989;2:817-21. 
8. Stanescu DC, Rodenstein DO, Hoeven C, Robert A. "Sensitive tests" are poor predictors of the decline in forced expiratory volume in one second in middle aged smokers. Am Rev Respir Dis 1987;135:585-90.

9. Buist AS. Current status of small airways disease. Chest 1984;86:101-5.

10. Becklake MR, Permutt S. Evaluation of tests of lung function for "screening" for early detection of chronic obstructive lung disease. In: Macklem PT, Permutt S, eds. The Lung in Transition Between Health and Disease, 12th edn. New York: Marcel Dekker Inc, 1979:345-87.

11. Hurst TS, Graham BL, Cotton DJ. Fast vs slow exhalation before $\mathrm{O}_{2}$ inhalation alters subsequent phase III slope. J Appl Physiol 1984;56:52-6.

12. Engel LA, Farhi LE. Airway closure, closing volume, and changes in inert gas mixing. In: Macklem PT, Permutt S, eds. The Lung in Transition Between Health and Disease, 12th edn. New York: Marcel Dekker Inc, 1979:153-82

13. Gelb AF, Hogg JC, Müller NL, et al. Contribution of emphysema and small airways in COPD. Chest 1996;109:353-9.

14. Hogg JC, Wright JL, Wiggs BR, Coxson HO, Saez AO, Paré PD. Lung structure and function in cigarette smokers. Thorax 1994;49:473-8.

15. Paiva M, Engel LA. Gas mixing in the lung periphery. In: Chang HK, Paiva M, eds. Respiratory Physiology. An Analytic Approach. Lung Biology in Health and Disease, vol 40. New York: Marcel Dekker, Inc, 1989:245-76.

16. Van Muylem A, De Vuyst P, Yernault J-C, Paiva M. Inert gas single-breath washout and structural alteration of respiratory bronchioles. Am Rev Respir Dis 1992;146:1167-72.

17. Paiva M, Van Muylem A, Ravez P, Yernault JC. Inspired volume dependence of the slope of the alveolar plateau. Respir Physiol 1984;56:309-25.

18. Crapo RO, Morris AH, Gardner RM. Reference spirometric values using techniques and equipment that meet ATS recommendations. Am Rev Respir Dis 1981;123:659-64.

19. Prabhu MB, Mink JT, Graham BL, Cotton DJ. Effect of a deep breath on gas mixing and diffusion in the lung. Respir Physiol 1990;79:195-204.

20. Graham BL, Mink JT, Cotton DJ. Implementating the three-equation method of measuring single breath carbon monoxide diffusing capacity. Can Respir J 1996;3:247-57.

21. Graham BL, Mink JT, Cotton DJ. Reproducibility of three equation diffusing capacity (DLco $\left.{ }^{\mathrm{SB}}-3 \mathrm{EQ}\right)$, mixing eficiency $\left(\mathrm{E}_{\mathrm{mix}}\right)$ and normalized phase three helium slope $\left(\mathrm{S}_{\mathrm{n}}\right)$ in normal subjects. Am J Respir Crit Care Med 1995;151:A786. (Abst)

22. Cotton DJ, Mink JT, Graham BL. Peripheral diffusion inhomogeneity is increased in smokers with normal lung function. Clin Invest Med 1994;17:B125. (Abst)
23. Cotton DJ, Prabhu MB, Mink JT, Graham BL. Effects of ventilation inhomogeneity on DLco ${ }^{\text {SB }}$-3EQ in normal subjects. J Appl Physiol 1992;73:2623-30.

24. Fowler WS. Lung function studies. II. The respiratory dead space. Am J Physiol 1948;154:405-16.

25. Paiva M, Verbank S, Van Muylem A. Diffusion-dependent contribution to the slope of the alveolar plateau. Respir Physiol 1988;72:257-70.

26. Crawford ABH, Makowska M, Kelly S, Engel LA. Effect of breath holding on ventilation maldistribution during tidal breathing in normal subjects. J Appl Physiol 1986;61:2108-15.

27. Hogg J, Brunton J, Brown J, Kryger M, Macklem PT. Gas diffusion across collateral channels. J Appl Physiol 1972;33:568-75.

28. Engel LA, Utz G, Wood LDH, Macklem PT. Ventilation distribution in anatomical lung units. J Appl Physiol 1974;37:194-200.

29. Crawford ABH, Makowska M, Paiva M, Engel LA. Convection- and diffusion-dependent ventilation maldistribution in normal subjects. J Appl Physiol 1985;59:838-46.

30. Prisk GK, Guy HJB, Elliott AR, Paiva M, West JB. Ventilatory inhomogeneity determined from multiple-breath washouts during sustained microgravity on Spacelab SLS-1. J Appl Physiol 1995;78:597-607.

31. Crawford ABH, Cotton DJ, Paiva M, Engel LA. Effect of lung volume on ventilation distribution. J Appl Physiol 1989;66:2502-10.

32. Graham BL, Mink JT, Cotton DJ. Effect of breath-hold time on DLco $^{\text {SB }}$ in patients with airway obstruction. J Appl Physiol 1985;58:1319-25.

33. Soparkar GR, Mink JT, Graham BL, Cotton DJ. Measurement of temporal changes in DLco ${ }^{\text {SB }}$-3EQ from small alveolar samples in normal subjects. J Appl Physiol 1994;76:1494-501.

34. Engel LA, Grassino A, Anthonisen NR. Demonstration of airway closure in man. J Appl Physiol 1975;38:1117-25.

35. Guy HJB, Prisk GK, Elliott AR, Deutschman RA III, West JB. Inhomogeneity of pulmonary ventilation during sustained microgravity as determined by single-breath washouts. J Appl Physiol 1994;76:1719-29.

36. Bryan AC, Milic-Emili J, Pengelly D. Effect of gravity on the distribution of pulmonary ventilation. J Appl Physiol 1966;21:778-84.

37. Leblanc P, Ruff F, Milic-Emili J. Effects of age and body position on airway closure in man. J Appl Physiol 1970;28:448-51.

38. Hoeppner VH, Cooper DM, Zamel N, Bryan AC, Levison H. Relationship between elastic recoil and closing volume in smokers and nonsmokers. Am Rev Respir Dis 1974;109:81-6. 


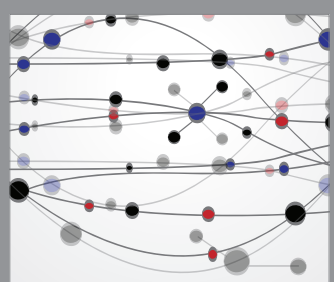

The Scientific World Journal
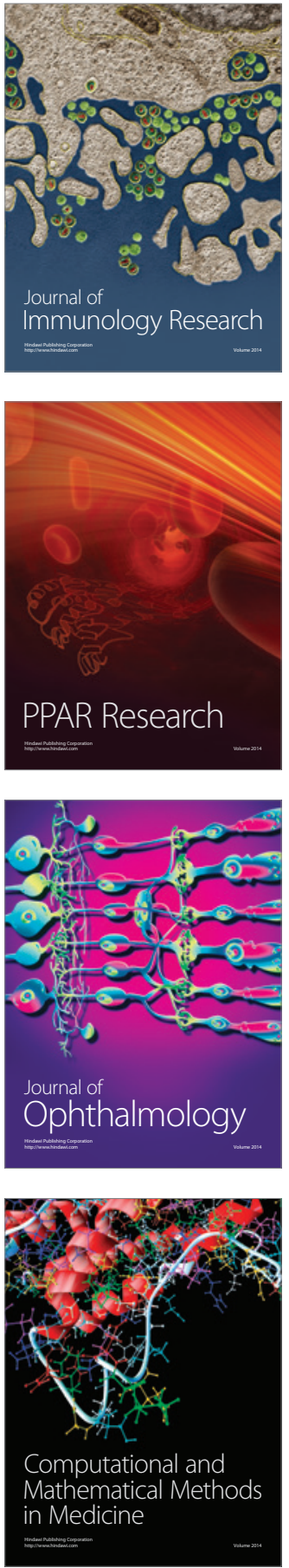

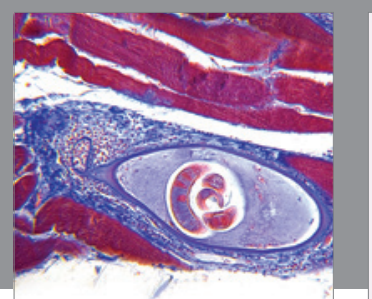

Gastroenterology Research and Practice

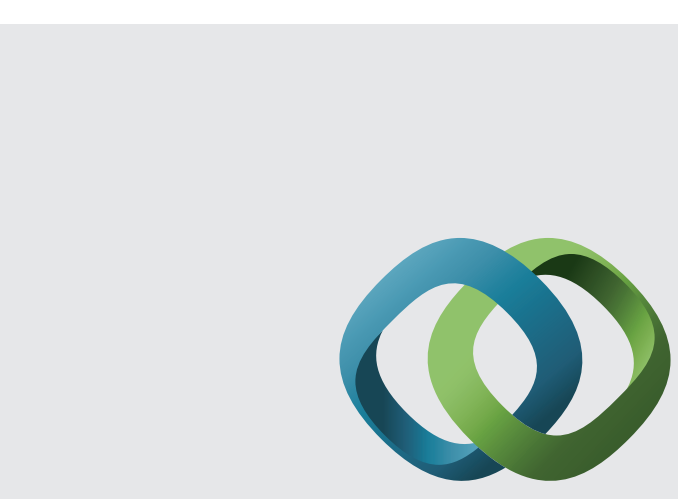

\section{Hindawi}

Submit your manuscripts at

http://www.hindawi.com
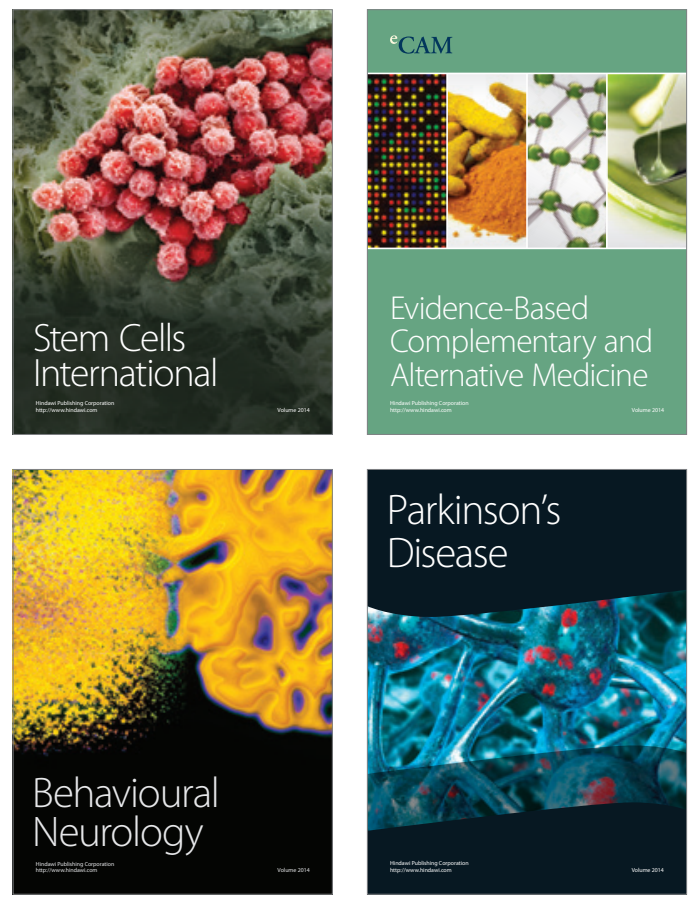
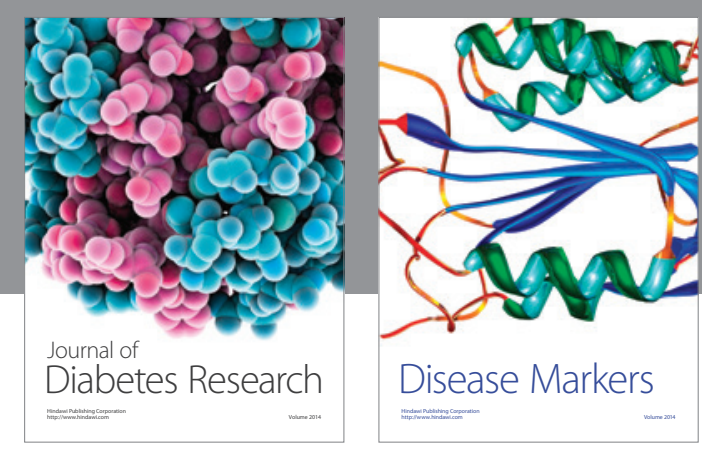

Disease Markers
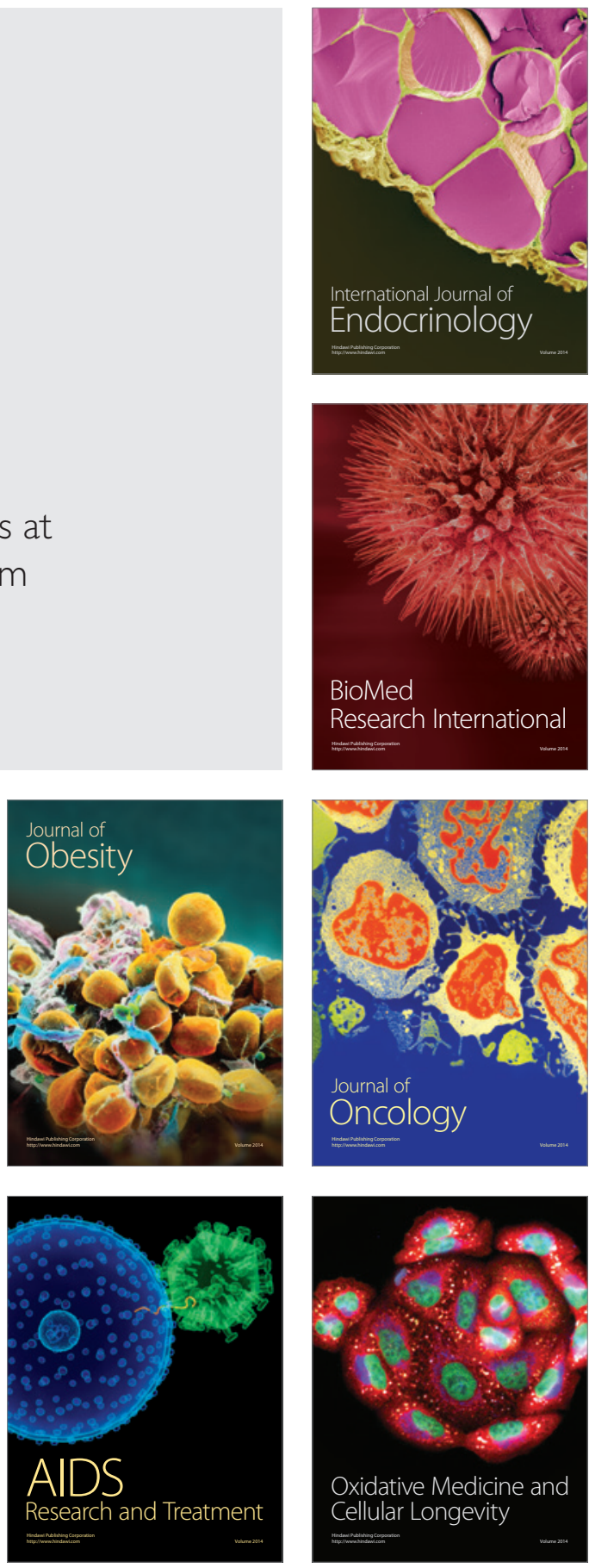